\title{
Part Family and Operations Group Formation for RMS Using Bond Energy Algorithm
}

\author{
Kamal Khanna ${ }^{\# 1}$, Rakesh Kumar ${ }^{* 2}$ \\ ${ }^{\# 1}$ PhD Research Scholar, Dept. of Mechanical Engineering, IKG PTU, Kapurthala, India \\ kksbs1@gmail.com \\ ${ }^{* 2}$ Dept. of Mechanical Engineering, Shaheed Bhagat Singh State Technical Campus, Ferozepur, India \\ rakesh1607@gmail.com
}

\begin{abstract}
In the present global scenario companies are forced to compete in product varieties and speed to market as well as in price. Reconfigurable Manufacturing Systems (RMSs) have been envisaged as a manufacturing paradigms to face these challenges. The foundation of RMS lies on the premise of group technology. The present work highlights the peculiarities of RMS vis a vis CMS, another group technology based manufacturing paradigm. It attempts to evolve a methodology for RMS cell formation; composition of part families and subsequently recognition of operation groups. Bond Energy Algorithm has been incorporated in the present work and considered as the foundation technique to structure the part family formation in RMS. The effectiveness of the methodology has been compared with some standard problems from the CMS cell formation literature and provides an outline for the RMS design which provides assuring manufacturing paradigm for future.
\end{abstract}

Keywords: Bond Energy Algorithm, Reconfigurable Manufacturing Systems, Seed Sub-Matrix

\section{INTRODUCTION}

Manufacturing companies in today's scenario are facing increasingly frequent and unpredictable market changes driven by global competition, including the rapid introduction of new products, reducing lead times, increasing quality and product variety [19],[26]. To remain competitive in such a scenario, companies must design manufacturing systems that not only produce high-quality products at low cost, but also allow for rapid response to market changes and consumer needs. Dedicated Manufacturing systems (DMSs) are capable of mass production but are incompetent to provide variety. Flexible manufacturing systems (FMSs) do respond to product changes; but they are not designed for structural changes [11] and therefore cannot respond to abrupt market fluctuations. It has been envisaged that the challenges posed by present-day global market environment could be faced if we have a responsive manufacturing system that can be created by incorporating basic process modules, both hardware and software, that can be rearranged quickly and reliability, allows adding, removing or modifying specific process capabilities, controls, software or machine structure to adjust production capacity in response to changing markets demands or technologies and provides customized flexibility for a particular part family and should be open ended, so that it can be improved, upgraded, and reconfigured, rather than replaced to accommodate demands or technologies [12],[15],[19],[27]. Keeping in view these factors, a new manufacturing system to fulfil these objectives was proposed in 1999, in the Engineering Research Centre (ERC) at the University of Michigan College Of Engineering. It was named as "Reconfigurable Manufacturing Systems (RMSs)" and described as, "A system designed at the outset for rapid change in its structure, as well as in its hardware and software components, in order to quickly adjust its production capacity and functionality within a part family in response to sudden market changes or intrinsic system change [27]. RMS has been envisaged to provide the exact functionality and capacity that is needed, exactly when it is needed. Thus it can be made to be a dedicated system or a flexible system or in between and can change as and when required [19].

\section{A. RMS Cell Formation}

Cell formation is a core issue in the implementation of all 'Group Technology' based Manufacturing systems' such as CMS, FMS, RMS etc. Cell formation includes two sub-problems: the identification of 'part families' and formation of 'machine groups' of 'production cells'. Part family formation provides a number of benefits in terms of manufacturing, design, purchasing etc. All parts in a family, depending on the purpose, may require similar treatment, handling and design features, enabling reducing setup times, improved scheduling, improved process control and standardized process plans. Part family formation, is therefore, a prerequisite for the efficient manufacture of parts in groups and is probably the main determinant for the overall effectiveness of the cell system of production [23]. In the Cellular Manufacturing systems, the machine groups are firstly 
made and then parts are assigned to those particular machine groups. Similarly to implement RMS in an industry, Part family formation is the first step. In the RMS cell formation, firstly the part families have been made according to their design and manufacturing attributes and after forming the part families, the operations sequences have been designed [19] and finally the machines are reconfigured based on the manufacturing requirements by changing their basic (slide ways, base, columns etc.) and auxiliary (tool changer, spindle head, spacer etc.) modules. The machines used in RMS are conventional machines but are designed in such a way that these can be reconfigured by changing their auxiliary modules (dynamic in nature) easily and quickly as these are smaller compared to basic modules (structural in nature) and hence can be economically and rapidly changed with less effort [7].

\section{B. Cell Formation Techniques}

In general, the procedure of cell formation can be grouped into three categories [25]:

$$
\text { -Machine groups identification (MGI) }
$$

-Part families' identification (PFI)

-Part families/machine grouping (PF/MG), these all are descriptive methods for the cell formation. Secondly, there are many mathematical programming approaches available in the literature like linear programming, dynamic programming, goal programming and linear \& quadratic integer programming. The third procedure to form the groups is based on the cluster analysis in which the elements have a high degree of similarity among them and a low degree of similarity with elements from different groups [16].These can be classified into three major techniques like Array based clustering in which it allocates machines to groups and parts to families, through re-ordering rows and columns of the incidence matrix. This is a machine-part index matrix whose values aij are 1 if machine $i$ operates on part $j$ and 0 otherwise, e.g. Bond energy analysis, Rank order clustering, MODROC, DCA etc.

Bond Energy analysis which was developed [14] and used in this proposed work to accomplish block diagonalization by applying permutations and combinations to rows and columns is a general purpose clustering algorithm that can be applied to any non-negative object-attribute matrix [23]. Rank order clustering [9] provides a simple, effective and efficient analytical technique in which each row and column read a binary word 1 and 0 ( 1 indicate element and 0 indicate void) and successively rearranging rows and columns by iterating in the decreasing order until no further iteration can be performed on the matrix. To further improve its computational efficiency ROC2 [10] and MODROC [3] have been developed by the researchers.

In Hierarchical clustering, the incidence matrix is divided into broad cells which are subdivided again and again until obtained group that cannot be further iterated. Its example is Dendogram, SLC [13] which assigns the largest value of the similarity coefficient possessed by a pair of machines from the two groups as the coefficient value for the two groups, ALC [22] to reduce the 'chaining' problem among the group of machines, whereas CLC [6] assigns the smallest value of the similarity coefficient possessed by a pair of machines from the two groups as the coefficient value for the two groups. In case of Non Hierarchical clustering techniques are iterating techniques that need the number of clusters in advance. These begin with a random initial partition of the data set. But these cannot lead to satisfactory results. Some of the non-hierarchical methods are ZODIAC [2] and GRAPHICS [24].

In the literature only few of the researchers have worked on the part family formation in RMS and from all those a unique methodology was proposed [19] and the authors have suggested that the part families' primary reconfiguration sequence and secondary reconfiguration sequence according to the various combinations of the basic modules and auxiliary modules in Reconfigurations Manufacturing Tools configurations. Their research has presented a logical and systematic procedure to group the parts into families and simultaneously an operation sequence has been selected from a set of operation sequences for each part. Therefore, an operation group corresponding to each part family has also been recognized in their research. A unique methodology to improve the reconfigurability of the RMSs using a multi objective optimization technique was developed by [7]. As Per [1], the authors proposed the need of mathematical model for the problem of family sequencing and operation sequencing inside each family. In the similar work, the authors have proposed a methodology that how to adjust the number of modules added, adjusted and removed for reconfiguring an part family formation in RMS [5].

Keeping in the view the availability of broad cell formation literature for different manufacturing paradigms such as CMS, FMS etc., instead of developing a new technique, we have attempted to recognise some of them to suitably adapt for RMS part family and operations group formation. 


\section{IMPORTANT TERMS \& CONCEPTS}

First the notations used in this work are given in sub-section A and thereafter, in sub-section B the common terms and concepts from the cell formation literature which are used in this work are briefly revisited and BEA algorithm is presented in sub-section $\mathrm{C}$.

\section{A. Terminology and Notations}

POIM: $\quad$ Part Operation Incidence Matrix

SSM: $\quad$ Seed Sub-Matrix

SRE: $\quad$ Seed Row Element

EASR: $\quad$ Elements Adjoining Seed Row (Already Identified)

ME: $\quad$ Measure of Effectiveness

$\mathrm{N}$ : Number of Rows

$\mathrm{S}_{\mathrm{ij}}$ : Jaccard's Similarity Index

$A_{i j} \quad\left\{\begin{array}{l}1, \text { if part 'i' requires processing on operation 'j' } \\ 0, \text { Otherwise }\end{array}\right.$

$\eta$ : $\quad$ Grouping Efficiency

\section{B. Terms and Concepts from Literature}

In Part Operation Incidence Matrix (POIM), the set of machines which are required to process each part is summarised in 0-1 form. The POIM size is $\mathrm{P} \times \mathrm{O}$. It is to note that the array of incidence does not explicitly consider the sequence of operations for individual parts. An example of 7 x 5, POIM is given in Table I.

TABLE I

Example of POIM

\begin{tabular}{|c|c|c|c|c|c|}
\hline $\begin{array}{c}\text { Operation } \\
\text { Part } \downarrow\end{array}$ & 1 & 2 & 3 & 4 & 5 \\
\hline 1 & 1 & 0 & 1 & 1 & 0 \\
\hline 2 & 1 & 0 & 0 & 1 & 0 \\
\hline 3 & 0 & 1 & 1 & 0 & 1 \\
\hline 4 & 0 & 1 & 1 & 0 & 1 \\
\hline 5 & 1 & 0 & 1 & 1 & 0 \\
\hline 6 & 0 & 1 & 0 & 0 & 1 \\
\hline 7 & 0 & 1 & 0 & 0 & 1 \\
\hline
\end{tabular}

Diagonalized POIM is a sub matrix of the part-operation incidence matrix formed by the intersection of columns representing operation family and rows representing a part family. The diagonalized POIM is generated from POIM using an algorithm to sort the matrix into best possible blocks. Examples of the most popular block diagonalization heuristics from CMS literature are Rank-order clustering (ROC), direct clustering analysis (DCA), Single Linkage Clustering (SLC), Complete Linkage Clustering (CLC), Average Linkage Clustering (ALC), Linear Cell Clustering (LCC) and Bond Energy Analysis (BEA) algorithm. These clustering methods also called matrix manipulation methods which attempt simultaneous grouping of parts and machines through block diagonalization by reordering rows and columns of the binary incidence matrix. Table II gives an example of Diagonalized POIM based on POIM given in Table I. In this work, the authors have used Bond Energy Analysis (ME) algorithm as the foundation technique in the proposed methodology. 
TABLE II

Example of Diagonalized POIM

\begin{tabular}{|c|c|c|c|c|c|}
\hline $\begin{array}{c}\text { Operation } \rightarrow \\
\text { Part } \downarrow\end{array}$ & 1 & 4 & 3 & 2 & 5 \\
\hline 2 & 1 & 1 & 0 & 0 & 0 \\
\hline 1 & 1 & 1 & 1 & 0 & 0 \\
\hline 5 & 1 & 1 & 1 & 0 & 0 \\
\hline 3 & 0 & 0 & 1 & 1 & 1 \\
\hline 4 & 0 & 0 & 1 & 1 & 1 \\
\hline 6 & 0 & 0 & 0 & 1 & 1 \\
\hline 7 & 0 & 0 & 0 & 1 & 1 \\
\hline
\end{tabular}

\section{Bond Energy Algorithms and Grouping Efficiency $\eta$}

In this section, BEA has been briefly described as per below:

1. Create an attribute affinity matrix in which each entry indicates the affinity between the two associate attributes. The entries in the similarity matrix are based on the frequency of common usage of attribute pairs [23].

2. The BEA then converts this similarity matrix to a BOND matrix in which the entries represent a type of nearest neighbour bonding based on probability of co-access. The BEA algorithm rearranges rows or columns so that similar attributes appear close together in the matrix.

3. Finally, the designer draws boxes around regions in the matrix with high similarity.

The resulting matrix, modified from, is illustrated in Table III. The two shaded boxes represent the attributes that have been grouped together into two clusters.

TABLE III

BEA Affinity Matrix

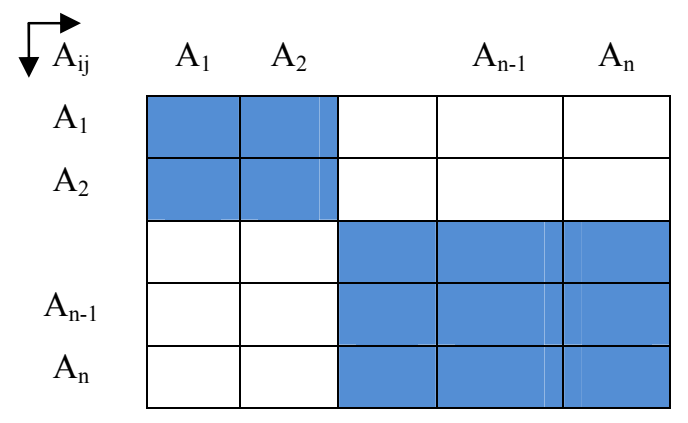

Two attributes $\mathrm{Ai}$ and $\mathrm{Aj}$ have a high affinity if they are frequently used together in database application. At the heart of the BEA is the global affinity measure. Suppose that a database consists of $n$ attributes $\left\{A_{1}, A_{2} \ldots A_{n}\right\}$. The global affinity measure, AM, is defined as

$$
\mathrm{AM}=\sum_{\mathrm{i}=1}^{\mathrm{n}}\left(\text { bond }\left(\mathrm{A}_{\mathrm{i}}, \mathrm{A}_{\mathrm{i}-1}\right)+\operatorname{bond}\left(\mathrm{A}_{\mathrm{i}}, \mathrm{A}_{\mathrm{i}+1}\right)\right.
$$

In [3], the quantitative measure of goodness of a solution, named grouping efficiency, which is weighted average of two functions and it is defined as

$$
\eta=q \eta_{1}+(1-q) \eta_{2}
$$

Where $\eta_{1}$ is the ratio of number of $1 \mathrm{~s}$ is the diagonal block to the total number of elements (both $0 \mathrm{~s}$ and $1 \mathrm{~s}$ ) in the diagonal blocks, $\eta_{2}$ is the ratio of number of 0 s are the diagonal block to the total number of elements (both $0 \mathrm{~s}$ and $1 \mathrm{~s})$ in the diagonal blocks, and $\mathrm{q}$ is the weighing factor $(0<\mathrm{q}<1)$. If $\mathrm{e}$ is the total number of ones in a machine-part incidence matrix, $o$ is the total number of zeros in the machine-part incidence matrix, $e_{1}$ is the number of $1 \mathrm{~s}$ is the diagonal block, $\mathrm{e}_{\mathrm{v}}$ is the number of voids is the diagonal block and $\mathrm{e}_{0}$ is the number of exceptional elements is the off-diagonal block, then grouping efficiency is given as:

$$
\eta=\mathrm{q}(\mathrm{e} 1 / \mathrm{e} 1+\mathrm{ev})+(1-\mathrm{q})(\mathrm{e} 0-\mathrm{ev} / \mathrm{e} 0-\mathrm{ev}+\mathrm{e} 0-\mathrm{e} 1)
$$




\section{PROBLEM FORMULATION}

The proposed methodology is an attempt to form part families in RMSs using the cell formation technique(s) available in the literature. In the present work, Diagonalized Part Operation Incidence Matrix has been taken as the initial matrix and in view of that as the above mentioned procedure; the part families have been formed and addresses the issue of cell formation in RMSs. The cell formation method for the formation of part families is taken on the priority and the operations groups are dealt subsequently. It has also been taken into account that the voids and exceptional elements should be least into the selected part family as it may increase the cost. In the present work few terms are conceptualised as described in the following sub-section.

\section{A. Seed Row Element, Seed Row and Seed Sub-Matrix}

Firstly calculate the ME of a given Diagonalized POIM and locate the element with the highest M.E i.e. $M . E=4$. The element which is having the highest M.E. is named as the Seed Row Element. The row which contains the seed row element is regarded as the Seed Row. By applying the Jaccard's Similarity Index (Sij), the part families and subsequent operation groups have been made by taking an acceptable value of $\mathrm{Sij} .>=0.60$. The sub-matrix consisting of part family and subsequent operation groups is named as Seed Sub-Matrix.

\section{DESCRIPTION of METHODOLOGY}

The proposed methodology for RMS cell formation (part family formation and identification of corresponding operation groups), depicted as a flow chart in Figure 1 has been divided into following procedural steps:

Step 1: Let us make a Diagonalized POIM using any standard POIM diagonalization method.

Step 2: Determine ME (Measure of Effectiveness) of each element for the diagonalized POIM.

Step 3: Set a counter variable ' $\mathrm{i}$ ' equal to 1 .

Step 4: Select $i^{\text {th }}$ row and Identify whether $i^{\text {th }}$ is the seed row or not (any element having maximum value of $\mathrm{ME}=4$ ). If $i^{\text {th }}$ row is not having value of $M E={ }^{\prime} 4$ ', then go to next row by incrementing $i^{\text {th }}$ value by one.

Step 5: If yes, then go to the next row i.e. $\mathrm{i}+1^{\text {th }}$ row and the check whether it has seed and the number of seed(s) in that row. Now compare the rows; $i^{\text {th }}$ and $i+1^{\text {th }}$.

Step 6: Select that row which is having more seeds of POIM and name it as 'Seed Row'.

Step 7: After Identifying 'Seed Row', apply the Jaccard's Similarity Index $\left(\mathrm{S}_{\mathrm{ij}}\right)$ to compare the rows in the upward and downward direction by take the value of $\mathrm{S}_{\mathrm{ij}}=0.60$

Step 8: Select the row(s) which is having $\mathrm{S}_{\mathrm{ij}}=0.60$ or above and include into the Sub Matrix and leaves the row(s) which is having the $S_{\mathrm{ij}}$ below 0.60 .

Step 9: The selected rows of the sub matrix form a part family and this sub matrix is named as 'Seed SubMatrix'.

Step 10: The Seed Sub-Matrix of POIM is now our RMS cell having rows identified as part family and columns identified as operation group.

Step 11: Check whether value of ' $\mathrm{i}$ ' is less than equal to ' $\mathrm{N}$ ' (maximum number of rows of POIM). If this is true we go to step 4 again and repeat steps from step 4 to step 10, otherwise the process is stopped and the all the 'Seed Sub-Matrix' lead to the formation of the RMS cells. After the above procedure, if some parts are not allotted among RMS cells, such cases will be dealt manually, by lowering the value of ME score and taking due consideration of trade off between exceptional elements and voids. 


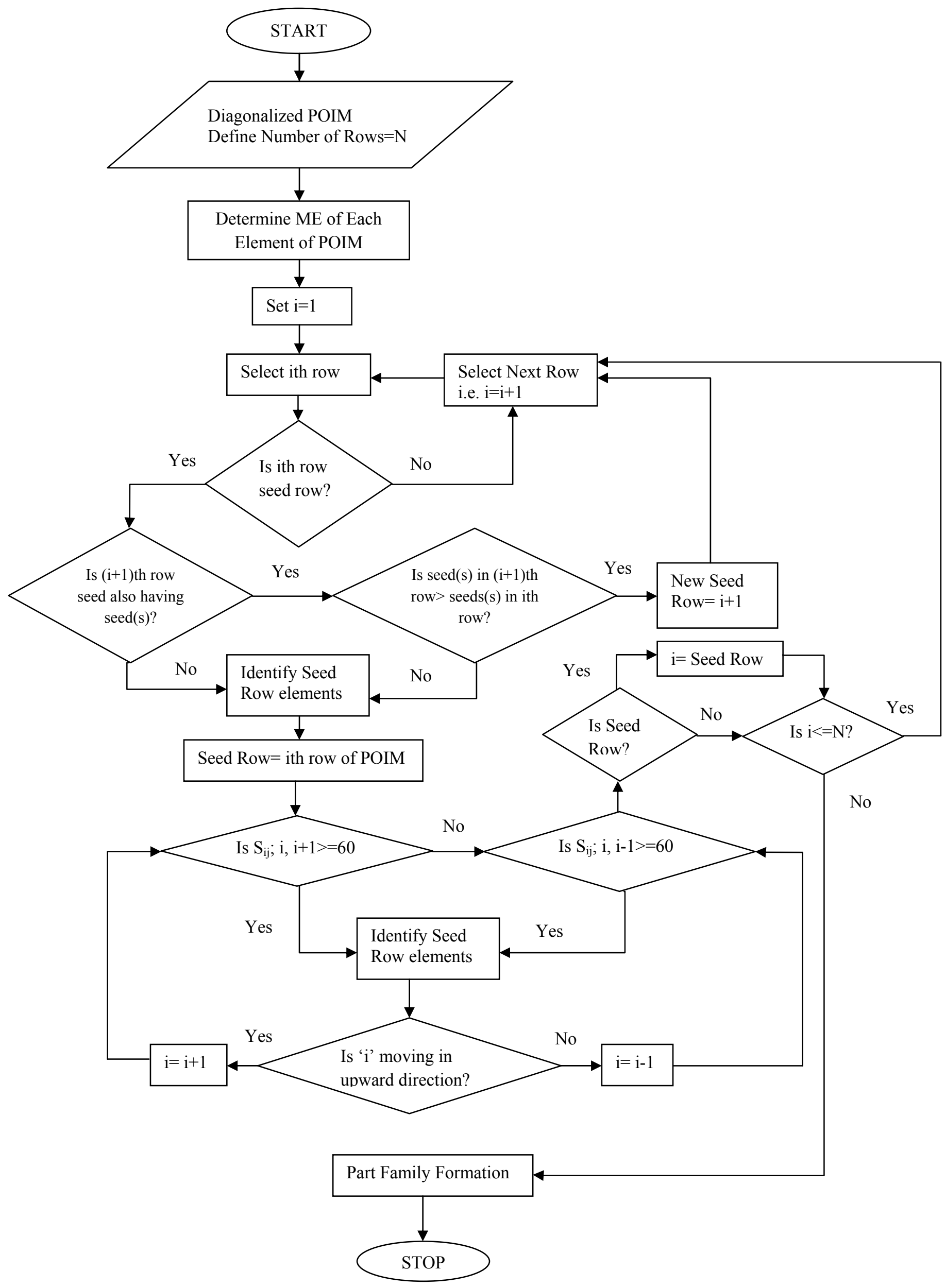


Fig.1. Flow Chart

\section{DEMONSTRATION THROUGH EXAMPLE}

Step 1: Let us make a Diagonalized POIM of 6x6 using any standard POIM diagonalization method.

Step 2: Determine ME (Measure of Effectiveness) of each element for the diagonalized POIM as in Table IV.

Step 3: The value of ' ' is set equal to ' 1 '.

Step 4: Now select that element which has the highest value of M.E i.e. M.E=4. In this example, an element (2, 3) becomes the first seed row element and the Row 2 becomes the first Seed Row of the POIM Matrix.

Step 5: Select $\mathrm{i}^{\text {th }}$ row and Identify whether $\mathrm{i}^{\text {th }}$ is the seed row or not (any element having maximum value of $\mathrm{ME}=4)$. In this example, row 2 is having the seed at $(2,3)$ and hence named it as the seed row.

Step 6: Now, after Identifying 'Seed Row', apply the Jaccard's Similarity Index $\left(\mathrm{S}_{\mathrm{ij}}\right)$ to compare the rows in the upward and downward direction by take the value of $S_{\mathrm{ij}}=0.60$. Here, we can see row 1 is having $\mathrm{S}_{\mathrm{ij}}>0.60$ and row 3 does not $S_{\mathrm{ij}}=0.60$ and therefore only row 1 is being selected.

Step 7: The row 1 and row 2 with operations group 1, 2 and 3 makes the first part family 1 and subsequent sub matrix is named as Seed Sub-Matrix. The same procedure is being followed for part $(3,4,5,6)$ and operations $(4,5,6)$ and therefore, part family 2 has been constituted.

Step 8: The Seed Sub-Matrix 1 and 2 of diagonalized POIM is now our RMS cell having rows identified as part family and columns identified as operation group.

Step 9: Check whether value of ' $\mathrm{i}$ ' is less than equal to ' $\mathrm{N}$ ' (maximum number of rows of POIM). If this is true we go to step 4 again and repeat steps from step 4 to step 10, otherwise the process is stopped and the all the 'Seed Sub-Matrix' lead to the part family formation of the RMS cells.

After the above procedure, if some parts are not allotted among RMS cells, such cases will be dealt manually, by lowering the value of ME score. Therefore, it can be seen that by calculating the M.E. of each element of the diagonalized POIM, the seed elements and seed rows are identified. Final formulation of part families and operation cells by POIM is given in Table V and Table VI.

TABLE IV

Diagonalized POIM

\begin{tabular}{|c|c|c|c|c|c|c|}
\hline $\begin{array}{c}\text { Operation } \rightarrow \\
\text { Part } \downarrow\end{array}$ & 1 & 2 & 3 & 4 & 5 & 6 \\
\hline 1 & 1 & 1 & 1 & 0 & 0 & 0 \\
\hline 2 & 1 & 1 & 1 & 0 & 0 & 0 \\
\hline 3 & 0 & 1 & 0 & 1 & 1 & 0 \\
\hline 4 & 0 & 0 & 0 & 1 & 1 & 1 \\
\hline 5 & 0 & 0 & 0 & 1 & 1 & 1 \\
\hline 6 & 0 & 0 & 0 & 0 & 1 & 1 \\
\hline
\end{tabular}

TABLE V

POIM after Applying ME (BEA)

\begin{tabular}{|c|c|c|c|c|c|c|}
\hline $\begin{array}{c}\text { Operation } \rightarrow \\
\text { Part } \downarrow\end{array}$ & 1 & 2 & 3 & 4 & 5 & 6 \\
\hline 1 & 1 & 3 & 2 & 0 & 0 & 0 \\
\hline 2 & 2 & 4 & 2 & 0 & 0 & 0 \\
\hline 3 & 0 & 1 & 0 & 2 & 2 & 0 \\
\hline 4 & 0 & 0 & 0 & 3 & 4 & 2 \\
\hline 5 & 0 & 0 & 0 & 2 & 4 & 3 \\
\hline 6 & 0 & 0 & 0 & 0 & 2 & 2 \\
\hline
\end{tabular}

\begin{tabular}{|l|}
\hline Seed Row 1 \\
\hline Seed Row 2 \\
\hline
\end{tabular}


TABLE VI

RMS Cell Formation

\begin{tabular}{|l|l|l|l|l|}
\hline \multicolumn{2}{|c|}{} & Parts & Operations & \\
\hline Cells & 1 & 1,2 & $1,2,3$ & Seed Sub-Matrix 1 \\
\hline & 2 & $3,4,5,6$ & $4,5,6$ & Seed Sub-Matrix 2 \\
\hline
\end{tabular}

\section{RESULTS}

The proposed algorithm is found to run satisfactorily with the diagonalized POIM by constraining Jaccard's Similarity index as equal to 0.60 . The methodology is applied on three standard problems taken from the literature as given in Table VII. The part family formation by this algorithm is tested by applying Grouping Efficiency measure $(\eta)$ and results are given in Table VII. The decisions regarding parts not allotted to any part family is taken manually after taking due consideration of trade off between exceptional elements and voids.

TABLE VII

'Seed Sub-Matrix' Results with Problems from Literature

\begin{tabular}{|l|l|l|l|l|l|l|}
\hline $\begin{array}{l}\text { Sr. } \\
\text { No. }\end{array}$ & Author(s) & \multicolumn{1}{|c|}{$\begin{array}{c}\text { Size } \\
\text { Parts x machines }\end{array}$} & $\begin{array}{c}\text { No of Seeds } \\
\text { Rows } \\
\text { Identified }\end{array}$ & $\begin{array}{c}\text { Part } \\
\text { Family (s) }\end{array}$ & $\begin{array}{c}\text { Grouping } \\
\text { Efficiency } \eta\end{array}$ & \multicolumn{1}{|c|}{ Remarks } \\
\hline 1 & Nagi ${ }^{17}$ & $20 \times 20$ & 05 & 05 & $81.54 \%$ & $\begin{array}{l}\text { Part } 4,9,14 \text { cannot } \\
\text { added into any part } \\
\text { family and their } \\
\text { decision can be taken } \\
\text { manually }\end{array}$ \\
\hline 2 & Sanakarn $^{19}$ & $10 \times 06$ & 02 & 02 & $81.25 \%$ & $\begin{array}{l}\text { Part 6annot added } \\
\text { into any part family }\end{array}$ \\
\hline 3 & $\begin{array}{l}\text { Rakesh } \\
\text { Kumar }^{21}\end{array}$ & $06 \times 06$ & 02 & 02 & $83.33 \%$ & No part left \\
\hline
\end{tabular}

\section{CONCLUSIONS \& FUTURE SCOPE}

The present work has presented a novel methodology for grouping parts into families, which is a central issue in the design of reconfigurable manufacturing systems. The efficiency of the reconfigurable manufacturing systems lies in the fact of making appropriate part families so that the system may be reconfigured again and again to meet the current market requirements. This attempt of making part families in RMSs takes into account the cell formation method from literature and in future more production parameters may be taken into account to make the part families for RMSs and thus more realistic results can be obtained.

\section{REFERENCES}

[1] A. Azab, B. Naderi, "Modelling the problem of production scheduling for reconfigurable manufacturing systems," Procedia CIRP vol. 33 , pp. $76-80,2015$.

[2] MP Chandrasekharan, R. Rajagopalan, "ZODIAC: an algorithm for concurrent formation of part families and machines cells", International Journal of Production Research, vol. 25, pp.835-850, 1987.

[3] MP Chandrasekharan, R. Rajagopalan, "An ideal seed non-hierarchical clustering algorithm for cellular manufacturing", International Journal of Production Research, vol. 24, pp. 451-463, 1986.

[4] MP Chandrasekharan, R. Rajagopalan, "MODROC: an extension of rank order clustering for group technology", International Journal of Production Research, vol. 24, pp. 121-1233, 1986.

[5] F. Hasan, P. K. Jain, D. Kumar, "Service Level as Performance Index for Reconfigurable Manufacturing System Involving Multiple Part Families", Procedia Engineering, vol. 69 pp. 814 - 821, 2014.

[6] T. Gupta, H. Seifoddinni, "Production data based similarity coefficient for machine-component grouping decisions in the design of a cellular manufacturing system”. International Journal of Production Research, Vol. 28, pp. 1247-1269, 1990.

[7] K. K. Goyal, P. K. Jain, M. Jain, "A novel methodology to measure the responsiveness of RMTs in reconfigurable manufacturing system", Journal of Manufacturing Systems, vol. 32, pp.724- 730, 2012.

[8] K. K. Goyal, P. K. Jain, M. Jain, "Operation Sequence Based Similarity Coefficient For RMS", Annals of DAAAM \& in the Proceedings of the 23rd International DAAAM Symposium, vol.23, pp. 281-284, Vienna, Austria, 2012.

[9] J.R. King, "Machine-component grouping in production flow analysis an approach", International Journal of Production Research, vol. 18, pp.117-133, 1980.

[10] J.R. King, V. Nakornchai, "Machine-component group formation in group technology: Review and extension", International Journal of Production Research, vol.20, pp. 117-133, 1982. 
[11] Y. Koren, "The global manufacturing revolution-product-process-business integration and reconfigurable systems" John Wiley \& Sons, 2010.

[12] M.G. Mehrabi, K. Ulsoy, Y. Koren, P. Heytler, "Trends and Perspectives in flexible and reconfigurable manufacturing systems, Journal of Intelligence Manufacturing, vol.13, pp.135-146, 2000.

[13] J. McAuley, "Machine grouping for efficient production", The Production Engineer, Vol. 51, pp.53-67, 1972.

[14] W.T. McCormick, P. Schweitzer, T. White, "Problem Decomposition and Data Reorganization by a Clustering Technique", Operations Research, vol. 20, pp. 993-1009, 1972.

[15] M.G. Mehrabi, K. Ulsoy, Y. Koren, P. Heytler, "Trends and perspectives in flexible and Reconfigurable Manufacturing Systems", Journal of Intelligent Manufacturing, vol.13, pp.135-146, 2002.

[16] R. Galan, J. Racero, I. Eguia, J.M. Garcia, "A systematic approach for product families formation in Reconfigurable Manufacturing Systems", Robotics and Computer-Integrated Manufacturing, vol.23, pp. 489-502, 2007.

[17] R. Nagi, G. Harhalakis and J. Proth. "Multiple routings and capacity consideration in group technology applications", International Journal of Production Research, vol.28, pp.2243-2257, 1990.

[18] S. Sankaran and R. Kasilingam, "An integrated approach to cell formation and part routing in group technology manufacturing system, Engg. Optimization, vol.16, pp.235-245, 1990.

[19] R Kumar., P.K. Jain, N K Mehta, "A Framework For Simultaneous Recognition Of Part Families And Operation Groups For Driving A Reconfigurable Manufacturing System, Advances In Production Engineering \& Management, vol. 5,pp. 45 - 58, 2010.

[20] R Kumar, "Comprehensive Design Strategy for a Reconfigurable Manufacturing System, PhD Thesis, Indian Institute of Technology, Roorkee, 2010.

[21] S. Sankaran and R. Kasilingam, "An integrated approach to cell formation and part routing in group technology manufacturing system”, Engg. Optimization, vol. 16, pp.235-245, 1990.

[22] H .Seifoddini, \& C.P. Hsu, "Comparative study of similarity coefficients and clustering algorithms in cellular manufacturing”, Journal of Manufacturing Systems, vol.13, pp.119-127, 1994.

[23] N. Singh, D. Rajamani, Cellular Manufacturing Systems (Design, planning and control), 1st edition. Chapman \& Hall Publishing Company, 1996.

[24] G. Srinivasan, T. Narendran, "GRAFICS - a non-hierarchical clustering algorithm for group technology". International Journal of Production Research, vol. 29,pp. 463-78, 1991.

[25] Wemmerlov, Hyer, "Research issues in CM implementation experiences and performance improvements", International Journal of Production Research, vol. 35, 29-49, 1987.

[26] Y Koren, M. Shpitalni, "Design of Reconfigurable Manufacturing Systems", Journal of Manufacturing Systems, vol.29, pp.130-141, 2010.

[27] Y. Koren, A. G. Ulsoy, "Engineering Research Centre for Reconfigurable Machining Systems, Creating the new manufacturing paradigm - exactly the functionality and capacity needed, exactly when needed", University of Michigan (ERC/RMS), 1999. (2013) http://shodhganga.inflibnet.ac.in/bitstream/10603/908/13/13_chapter\%201.pdf

\section{AUTHOR PROFILE}

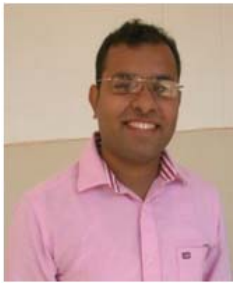

Kamal Khanna is currently pursuing his $\mathrm{PhD}$ in Mechanical Engineering from I.K.G Punjab Technical University, Kapurthala, INDIA and presently working as Lecturer in the Department of Mechanical Engineering, Shaheed Bhagat Singh State Technical Campus (Poly Wing), Ferozepur (A Punjab Govt. Establishment), India. He received his M-Tech. Degree from SLIET, Longowal with Distinction and B-Tech from I.K.G. Punjab Technical University, Kapurthala. He is a Life member of International Association of Engineers, Hong Kong, ISTE and Punjab Academy of Sciences. He has already published papers in different International Journals and Conferences. His areas of interests are Operations Management, RMS and Simulation Modeling of Manufacturing Systems.

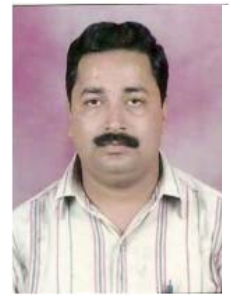

Dr. Rakesh Kumar is Associate Professor in the Department of Mechanical Engineering, Shaheed Bhagat Singh State Technology Campus (A Punjab Govt. Establishment), India. He obtained his $\mathrm{PhD}$ in the field of Reconfigurable Manufacturing Systems (CIMS-CAM) from Manufacturing Systems Lab., Department of Mechanical \& Industrial Engineering, Indian Institute of Technology (IIT), Roorkee, India. He is a life member of ISTE and Member, Society of Operations Management. He has published more than forty papers in International journals, National journals and conference proceedings. His areas of interest are Relational studies of social and cultural evolution and emergence of contemporary paradigms of Manufacturing Systems, Simulation Modeling of Manufacturing Systems, Manufacturing Systems (RMS, CMS)/ G.T., Cleaner Production Systems/ C. P. A. 